\title{
COMMENT \\ Making the case for ACEs: adverse childhood experiences, obesity, and long-term health
}

\author{
Joyce R. Javier ${ }^{1}$, Lucas R. Hoffman ${ }^{2}$ and Shetal I. Shah ${ }^{3}$, on behalf of the Pediatric Policy Council \\ Pediatric Research (2019) 86:420-422; https://doi.org/10.1038/s41390-019-0509-2
}

Adverse childhood experiences are traumatic events suffered by people aged $<18$ years. These adverse experiences can include abuse, neglect, and witnessing crime, parental conflict, mental illness, and substance abuse. Adverse childhood experiences have been linked to risky behaviors, chronic health conditions, and early death, resulting in stress that can derail healthy brain development. Adverse experiences also increase risks for dozens of illnesses and unhealthy behaviors, including smoking, alcoholism, depression, heart disease, suicide, unintended pregnancy, human immunodeficiency virus/sexually transmitted diseases, and cancer. ${ }^{1}$ The risk for these poor outcomes increases with each adverse experience. ${ }^{2}$

In this month's issue of Pediatric Research, Gardner et al. describe how adverse childhood experiences before age 9 years increases the odds of obesity in adolescence. ${ }^{3}$ Of note, the authors considered the effects of many adverse childhood experiences beyond those included in an earlier study known as the "ACEs study $^{\prime 2}$; for simplicity, we refer here to all such adverse childhood experiences as ACEs. Among these additional, stress-inducing experiences were death of a parent, close family member or a close friend; relocation; need for a foster home; serious illness of the child or a family member; and parental conflict.

These results contribute substantially to the collective evidence that ACEs adversely impact the subsequent health of children, an effect compounded by poverty. Collectively, these findings support the need to consider social determinants when developing behavioral strategies for promoting healthy development, including weight status, particularly in early adolescence.

The presence of ACEs does NOT condemn a child to poor adultonset outcomes. Protective factors prevent children from experiencing adversity and can defend against many associated, negative health outcomes. The Centers for Disease Control (CDC) has recommended five activities to prevent the impact of ACEs: strengthen economic supports to families, change social norms to support parents and positive parenting, provide quality early-life child care and education, enhance parenting skills, and intervene to mitigate harm and prevent future risk (i.e., enhanced primary care, parenting programs, treatment to lessen harms of abuse and neglect). ${ }^{4}$ For instance, Brotman et al. demonstrated that supporting parents by offering evidence-based parenting interventions during preschool can promote healthy child development and prevent obesity during adolescence. ${ }^{5}$

The weight of this evidence has already motivated changes in clinical practice, school policies, and legislation at state and local levels, all aiming to mitigate the long-term effects of ACEs. For example, the California legislature passed ACR $155{ }^{6}{ }^{6}$ encouraging policies to reduce ACEs, in 2014; and in 2017, Vermont passed bill No. 43, H. 508, aiming to screen for and address ACEs in schools and health-care clinics. ${ }^{7}$ In response to the growing evidence for lasting and progressive adverse effects of ACEs on diverse health outcomes and recognizing the complexity, scale, and difficulty involved in addressing this issue, the CDC now provides extensive educational resources and prevention strategies, including information to foster safe and nurturing environments and relationships for children, and technical packages to prevent childhood abuse and neglect. ${ }^{4}$ Efforts such as these demonstrate the growing recognition that the health-care industry plays a critical role in screening our pediatric patients for ACEs and intervening appropriately.

Increased attention to early childhood adversity may achieve multiple public health benefits. ${ }^{8}$ However, modern pediatric practices face daunting hurdles in operationalizing recommendations to screen for ACEs. Despite the evidence for benefit, thirdparty payors are not widely incentivizing screening with additional reimbursement. ${ }^{9,10}$ Screening for ACEs necessitates access to referral sources, which are often lacking.

Obtaining mental health services, for example, is becoming increasingly difficult as psychiatric providers participate in fewer insurance plans. ${ }^{11}$ For instance, $<50 \%$ of psychiatrists nationwide currently accept Medicaid, the primary insurer (with the Children's Health Insurance Plan [CHIP]) for 45 million (48\%) US children. Unfortunately, Medicaid enrollment is itself a risk factor for ACEs. ${ }^{12,13}$ For other referrals indicated by ACEs screening, pediatric insurance networks limit access to subspecialists, further impeding access to care. ${ }^{14}$ In the face of these challenges, it is unsurprising that only $\sim 4 \%$ of pediatricians reportedly screen for all major ACEs known to be associated with long-term sequelae. ${ }^{15}$ As payors migrate toward value-based payment strategies, however, opportunities exist to incentivize widespread screening for ACEs. Payment reform advocates maintain that the primary value of pediatric care is prevention of adult-onset disease. ${ }^{16}$ Following this logic, small, highly vulnerable pediatric populations should warrant increased, earlier attention and increased health-care resources. ${ }^{17,18}$

States are actively adopting screenings for parental health issues, such as post-partum depression and smoking, as part of both pediatric and maternal value-based care. ${ }^{19}$ Reporting these metrics and achieving performance targets would merit increased

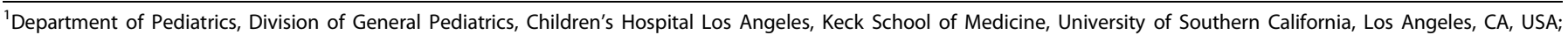

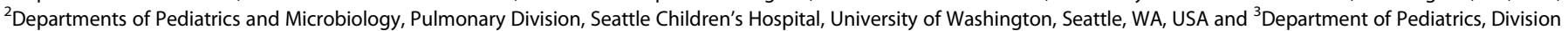
of Neonatology, Maria Fareri Children's Hospital at Westchester Medical Center, New York Medical College, New York, NY, USA

Correspondence: Joyce R. Javier (jojavier@chla.usc.edu)

Received: 2 July 2019 Accepted: 8 July 2019

Published online: 22 July 2019 
payment. Within appropriate patient-centered medical homes, Medicaid, and pediatric-specific Accountable Care Organizations, reforms such as these have resulted in increased compliance with screening recommendations, providing a template for implementing assessments of ACEs. ${ }^{9}$

Capitalizing on the promise of Value-Based Payment models for addressing ACEs in health-care settings will require several reforms. Financing must adequately reward pediatricians who go beyond screening. The findings of studies such as Gardner et al. demonstrate that the impact of ACEs is compounded by poverty; therefore, payment strategies must risk-adjust to reflect time spent caring for patients of lower socio-economic status. ${ }^{3}$ Efforts that would require support include seeking and developing appropriate referral patterns and establishing the community partnerships integral to addressing the impacts of adversity in atrisk children. ${ }^{20,21}$ High-value care extends beyond the confines of well-child visits; monitoring and supporting patient adherence, addressing barriers to care access, and measuring and interpreting long-term outcomes for individual patients are all essential, and all generally occur outside of examination rooms. To optimally break the affiliation between ACEs and obesity, it has been suggested that health-care providers also support eligibility and enrollment for school meal programs, assist with alleviating community stress caused by food deserts, and macroscopically, promote nutritional standards for programs favored by the Supplemental Nutrition Assistance Program (SNAP). ${ }^{22}$ Such advocacy efforts by pediatricians on behalf of childhood health, while of predictably outsize impact throughout our patients' lives, rarely receive formal support.

As the inaugural step in addressing ACEs and their consequences is screening, children at highest risk must have access to care, underscoring the fundamental importance of continuous enrollment in health insurance. Absent a pediatrician to perform the screening, coordinate care, and report data in exchange for incentives, the system fails. Unfortunately, recent data demonstrate a decline in the number of insured children. Children with multiple risk factors for adversity primarily obtain health coverage via social programs. ${ }^{23}$ However, enrollment in CHIP and Medicaid declined by 828,000 in 2018, representing the second straight year of decreased childhood insurance rates, yet only the second decrease in over two decades. ${ }^{24}$ The proportion of uninsured children rose from $4.7 \%$ to $5 \%$, reflecting 276,000 children, and the first increase since passage of the Affordable Care Act (ACA). ${ }^{25}$

Losses in coverage coincide with several policies aimed at heightening barriers faced by parents of socially at-risk children in obtaining health insurance. Recent administrative actions delayed funding to programs aiming to facilitate enrollment among children eligible for CHIP. ${ }^{26}$ Simultaneously, several states used the Medicaid Waiver program to create barriers, including establishing lockout periods and eliminating retroactive coverage; as a result, parents may be unaware that their children were uninsured until presenting for care. ${ }^{27}$ A further $90 \%$ reduction in funds to advertise public insurance programs, provide health insurance navigators, and foster community partnerships has exacerbated the decline in coverage. Owing to the association of these funds with the ACA, the past 2 years have seen a reduction in grants for outreach by $\$ 90$ million and for consumer programs by $\$ 53$ million. 24,28

The timing of these trends is particularly unfortunate; consumer assistance was perhaps more urgently needed as states created increasingly complicated bureaucracies for maintaining enrollment in public insurance programs. Many prospective customers now face lengthy renewal packets, multiple reviews to ensure eligibility, automatic disenrollment, and decoupled enrollment from other programs children utilize, such as the Women, Infants and Children Program and SNAP. Such hurdles further hamper alleviating the impact of ACEs. ${ }^{24,29}$
Studies such as Gardner et al. reinforce the importance of pediatric health care in fostering the social, as well as medical, conditions for children to become healthy adults. For children with multiple ACEs, pediatricians are no longer alone in ensuring this transition. Fortifying children's social supports to reduce adversity pays dividends by preventing more costly adult disease, such as the consequences of obesity. At a time of financial deprivation and administrative obstruction among those programs dedicated to both identify and address ACEs and to assist children who experience them, pediatricians must use their trusted voices. By making the business, economic, and moral "cases" for protection from adversity and its consequences as a preventive health strategy, physicians and scientists can provide critical and reliable rationale for preserving, expanding, and/or streamlining evidenced-based programs that assist children. ${ }^{30,31}$

Pediatricians can also participate in Value-Based programs, develop referral services, and support only metrics that directly impact child health. Pediatricians must proactively call attention to actions that damage the pediatric social safety net, emphasizing the outsize impact they have for children who experience childhood adversity using an ACE framework. Robert Virchow said, "Medicine is social science, and politics is nothing else but medicine on a large scale." ${ }^{32}$ Pediatricians must continue serving as leaders in protecting and advancing the best "medicine" for the children whose health we safeguard.

\section{PEDIATRIC POLICY COUNCIL}

Scott Denne, MD, Chair, Pediatric Policy Council; Shale Wong, MD, MSPH, PPC Representative, Academic Pediatric Association; Jean Raphael, MD, MPH, PPC Representative, Academic Pediatric Association; Jonathan Davis, MD, PPC Representative, American Pediatric Society; DeWayne Pursley, MD, MPH, PPC Representative, American Pediatric Society; Tina Cheng, MD, MPH, PPC Representative, Association of Medical School Pediatric Department Chairs; Michael Artman, MD, PPC Representative, Association of Medical School Pediatric Department Chairs; Shetal Shah, MD, PPC Representative, Society for Pediatric Research; Joyce Javier, MD, MPH, MS, PPC Representative, Society for Pediatric Research

\section{AUTHOR CONTRIBUTIONS}

J.R.J. and L.H. drafted the manuscript and provided critical revision of the manuscript for intellectual content. S.I.S. drafted the manuscript, provided critical revision of the manuscript for intellectual content, and supervised the writing of the manuscript.

\section{ADDITIONAL INFORMATION}

Competing interests: The authors are members of the Society for Pediatric Research Advocacy Committee, whose mission is to provide leadership in child advocacy through government and public forums for issues related to the mission of the Society. We recommend public and government priorities for advocacy and advocate for prioritized issues in partnership with other agencies and societies and community effectively with the SPR Council and membership regarding advocacy committees. Our multidisciplinary team provides a unique lens for the development of this SPR Perspectives review.

Publisher's note: Springer Nature remains neutral with regard to jurisdictional claims in published maps and institutional affiliations.

\section{REFERENCES}

1. Ramiro, L. S., Madrid, B. J. \& Brown, D. W. Adverse childhood experiences (ACE) and health-risk behaviors among adults in a developing country setting. Child Abus. Negl. 34, 842-855 (2010).

2. Dube, S. R., Anda, R. F. \& Felitti, V. J. Childhood abuse, household dysfunction, and the risk of attempted suicide throughout the life span: findings from the Adverse Childhood Experiences Study. JAMA 286, 3089-3096 (2001).

3. Gardner, R. F. A., Layte, R., Williams, J. \& McGavock, J. Adverse child experiences increase the odds of obesity in early adolescence: a population-based prospective cohort study. Pediatr. Res. https://doi.org/10.1038/s41390-019-0414-8 (2019). 
Making the case for ACEs: adverse childhood experiences, obesity, and... JR. Javier et al.

4. Fortson, B. L. et al. Preventing Child Abuse and Neglect: A Technical Package for Policy, Norm, and Programmatic Activities (Division of Violence Prevention, National Center of Injury Prevention and Control, Centers for Disease Control and Prevention, Atlanta, GA, 2016).

5. Brotman, L., Dawson-McClure, S. \& Huang, K.-Y. Early childhood family intervention and long-term obesity prevention among high-risk minority youth. Pediatrics 129, e621-e628 (2012).

6. 2014 California Legislature-2013-14 Regular Session, Assembly Concurrent Resolution No. 155. Available at http://www.leginfo.ca.gov/pub/13-14/bill/asm/ ab_0151-0200/acr_155_bill_20140528_introduced.htm.

7. 2017 No. 43. An act relating to building resilience for individuals experiencing adverse childhood experiences. Available at https://legislature.vermont.gov/ Documents/2018/Docs/ACTS/ACT043/ACT043\%20As\%20Enacted.pdf.

8. Gilbert, L. K. et al. Childhood adversity and adult chronic disease: an update from ten states and the District of Columbia, 2010. Am. J. Prev. Med. 48, 345-349 (2015).

9. Kelleher, K. J. et al. Cost saving and quality of care in a pediatric accountable care organization. Pediatrics 135, e582-e589 (2015).

10. Jonas, J. E. J., Noonan, K., Rubin, D. \& Fieldston, E. Shifting the care and payment paradigm for vulnerable children. Children's Hospital of Philadelphia, Policy Lab Center to Bridge Research, Practice and Policy, "Evidence to Action". Available at https://policylab.chop.edu/sites/default/files/pdf/publications/PolicyLab_EtoA_ ShiftingCarePaymentParadigm_2015.pdf (Accessed 1 Jun 2019).

11. Bishop, T. F., Press, M. J., Keyhani, S. \& Pincus, H. A. Acceptance of insurance by psychiatrists and the implications for access to mental health care. JAMA Psychiatry 71, 176-181 (2014).

12. Gilbert, L. K. et al. Childhood adversity and adult chronic disease: an update from ten states and the District of Columbia, 2010. Am. J. Prev. Med 48, 345-349 (2015).

13. Finkelhor, D., Turner, H. A., Shattuck, A. \& Hamby, S. L. Prevalence of childhood exposure to violence, crime, and abuse: results from the national survey of children's exposure to violence. JAMA Pediatr. 169, 746-754 (2015).

14. Wong, C. A., Kan, K., Cidav, Z., Nathenson, R. \& Polsky, D. Pediatric and adult physician networks in affordable care act marketplace plans. Pediatrics 139, e20163117 (2017)

15. Garner, A. S. et al. Promoting early brain and child development: perceived barriers and the utilization of resources to address them. Acad. Pediatr. 17, 697-705 (2017)

16. Raphael, J. L. \& Giardino, A. P. Accounting for kids in accountable care: a policy perspective. Clin. Pedia. (Philos.) 52, 695-698 (2013).

17. Kuo, D. Z. et al. Variation in child health care utilization by medical complexity. Matern. Child Health J. 19, 40-48 (2015).

18. Health, B. Value-based payment models for Medicaid child health services. Schuyler Center for Analysis and Advocacy and United Hospital Fund (2016) Available at http://www.bailit-health.com/articles/2016-0713-Bailit-vbf-final.pdf (Accessed 1 Jun 2019).
19. United Hospital Fund. You get what you pay for: measuring quality in valuebased payment for children's health care. United Hospital Fund Report (2016). Available at http://partnersforkids.org/wp-content/uploads/2017/09/You_Get_ What_You_Pay_For_Special_Report.pdf (Accessed 1 Jun 2019).

20. Hudak, M. L., Helm, M. E. \& White, P. H. Principles of child health care financing. Pediatrics 140, e201720 (2017).

21. Shonkoff, J. P. \& Garner, A. S. The lifelong effects of early childhood adversity and toxic stress. Pediatrics 129, e232-e246 (2012).

22. Hassink, S. Childhood obesity: how to battle an unrelenting epidemic (2018). Available at https://www.aap.org/en-us/aap-voices/Pages/Childhood-Obesity. aspx (Accessed 1 Jun 2019).

23. Shah, S. I. \& Brumberg, H. L. Predictions of the affordable care act's impact on neonatal practice. J. Perinatol. 36, 586-592 (2016).

24. Brooks, T. P. E. \& Roygardner, L. Medicaid and CHIP enrollment decline suggests the child uninsured rate may rise again (2019). Georgetown University Health Policy Institute, Center for Children and Families. Available at https://ccf. georgetown.edu/wp-content/uploads/2019/05/Medicaid-and-CHIP-EnrollmentDecline_Report.pdf (Accessed 1 Jun 2019). pp 1-25.

25. Alker, J. P. O. Nation's progress on children's health coverage reverses course (2018). Georgetown University Health Policy Institute, Center for Children and Families. Available at https://ccf.georgetown.edu/wp-content/uploads/2018/11/ UninsuredKids2018_Final_asof1128743pm.pdf (Accessed 1 Jun 2019). pp. 1-15.

26. Whitener, K. Outreach and enrollment grants to miss critical back-to-school period due to CHIP funding delay (2018). Georgetown University Health Policy Institute, Center for Children and Families. Available at https://ccf.georgetown. edu/2018/05/14/outreach-and-enrollment-grants-to-miss-critical-back-to-schoolperiod-due-to-chip-funding-delay/ (Accessed 1 Jun 2019).

27. Rivkees, S. A., Opipari, V. \& Denne, S. Commentary from the pediatric policy council 2018: the year of living dizzyingly. Pedia. Res 85, 115-117 (2019).

28. Gollust, S. E. et al. TV advertising volumes were associated with insurance marketplace shopping and enrollment In 2014. Health Aff. (Millwood) 37, 956-963 (2018).

29. Rudowitz, R., Hinton, E. \& Antonisse, L. Medicaid enrollment \& spending growth: FY 2018 \& 2019. Kaiser Family Foundation. Issue Brief (2018). Available at http:// files.kff.org/attachment/Issue-Brief-Medicaid-Enrollment-and-Spending-GrowthFY-2018-2019 (Accessed 1 Jun 2019).

30. Garner, A. S. \& Shonkoff, J. P. Early childhood adversity, toxic stress, and the role of the pediatrician: translating developmental science into lifelong health. Pediatrics 129, e224-e231 (2012).

31. Javier, J. R., et al. Promoting enrollment in parenting programs among a Filipino population: a randomized trial. Pediatrics 143, e20180553 (2019).

32. Rudolf Virchow Quotes. Available at https://www.azquotes.com/author/29202Rudolf_Virchow (Accessed 10 Jun 2019). 